\title{
What Drives Female Entrepreneurship in Japan?
}

\author{
Ayumi Inaba and Shing-Wan Chang
}

\begin{abstract}
Although the number of female entrepreneurs has grown worldwide (Brush and Cooper 2012; Kelley et al. 2013), female self-employment rate in Japan is quite low and there is still a significant gap of entrepreneurship participation between men and women (Welsh et al. 2014). One of the possible reasons why Japanese women are not willing to get self-employed is a Japanese cultural norm, which regards business as the masculine activity and housework as the women's responsibility (Kimoto 2000; Kondo 2001). This strong gender-role perception still affects females' behaviours. For instance, they tend to keep a distance from social capital/relationships and prefer kinship (Brush et al. 2009; Marlow 1997).

The purpose of this study is to examine factors affecting Japanese female entrepreneurship, specifically to find out the impacts of gender stereotypical perception and online social capital obtained via social media on entrepreneurial intention in Japan. The analysis was based on 426 Japanese entrepreneurs consisting of 243 business owners and 183 nascent entrepreneurs. To test the hypotheses and moderating effects of gender and age on entrepreneurial intention, Structural Equation Modelling and Independent Samples $t$-test were conducted. Results show that gender stereotypes, which referred to business as males' activity and housework as females' responsibility, would still exist in Japan and it decreased women's intention to start their own business. However, the effectiveness of social media to increase females' access to online social capital was also identified. Moreover, gender and age were found to be significant moderators for all hypothesized relationships. These findings can help policymakers understand women entrepreneurial intentions in Japan and take measures to extend their business opportunities. Lastly, this study provides the theoretical implications and extends the entrepreneurship literature.
\end{abstract}

References available upon request.

\author{
A. Inaba $(\bowtie) \cdot$ S.-W. Chang \\ Middlesex University, London, UK \\ e-mail: ayumi19860130@gmail.com; s.chang@mdx.ac.uk
}

